Agenda Internacional

Año XXVI N³7, 2019, pp. 61-87

ISSN 1027-6750

\title{
Los ciclos de política exterior peruana focalizados en la solución de las controversias fronterizas
}

\author{
José Boza*
}

\begin{abstract}
RESUMEN
Desde el año 1900 el Perú ha tenido dos ciclos durante los cuales la Cancillería enfocó su atención en la solución de las controversias fronterizas. El primero, desde 1902 hasta 1942, concentró los esfuerzos en las negociaciones para delimitar el territorio nacional con sus cinco vecinos. El segundo ciclo, entre los años 1995 y 2014, estuvo dedicado a resolver los diferendos fronterizos pendientes, incluyendo culminar la ejecución de los tratados limítrofes con Ecuador y Chile, así como definir la delimitación marítima con esos dos países. En suma, en la mitad del tiempo transcurrido desde el año 1900 la política exterior peruana ha estado focalizada en la solución pacífica de controversias sobre los límites internacionales del país.
\end{abstract}

Palabras clave: controversias fronterizas, política exterior, solución pacífica de controversias.

\section{Peruvian foreign policy cycles focused on solving boundary disputes}

\section{Abstract}

Peru has had since 1900 two periods focused on solving boundary disputes. The first one, from 1902 to 1942, aimed efforts at negotiations to fix Peru's international borders with its five neighbors. The second one, between 1995 and 2014, aimed at solving all pending

\footnotetext{
* Licenciado en Relaciones Internacionales (ADP, Lima, 1990). Maestría en Promoción Económica Internacional (ADP, Lima, 2011). Diplomado en Relaciones Chile-Perú (IEI, Universidad de Chile, Santiago, 2012). Diplomático de carrera. Asesor y miembro de las comisiones de negociación y de demarcación fronteriza entre Perú y Ecuador (1997-1999), gerente de gestión de la APCI (2005), miembro del Gabinete de Ministro (2006-2008), jefe de la Oficina General de Comunicación (2014-2015), jefe de Gabinete de Viceministro (2016) y jefe de Gabinete de Ministro (2016-2019). Ha desempeńado funciones en las embajadas del Perú en Estados Unidos (1992-1996), Francia (1999-2004) y Chile (2008-2014) y fue cónsul general en Santiago de Chile (2012-2013). Actualmente ejerce el cargo de representante permanente del Perú ante la Organización de Estados Americanos. Labores de docencia: Curso de Relaciones entre Estados Unidos y América Latina, Escuela de Gobierno y Gestión Pública, USMP, 2007. Curso de Conflicto, Negociación y Mediación, Facultad de RR.II. USIL, 2014. Curso de Globalización y Sistema Internacional, Escuela de Gobierno y Gestión Pública, USMP, 2016-2018. Cursos de Negociación e Historia Diplomática del Perú y Política Exterior, ADP, 2016-2018. Correo electrónico: josembozao@gmail.com
}

iD https://orcid.org/0000-0003-2725-3641 
boundary issues, including fully implementing boundary treaties with Ecuador and Chile, as well as defining maritime limits with both countries. In sum, half of the time elapsed since the year 1900 Peru's foreign policy centered on solving peacefully disputes regarding the country's international boundaries.

Keywords: boundary disputes, foreign policy, peaceful means of conflict-resolution.

\section{Introducción}

No es extraño que la problemática fronteriza haya sido un tema recurrente para la diplomacia peruana. La república nació rodeada literalmente de territorios en disputa con todos sus vecinos y esa situación no mejoró durante el transcurso del siglo XIX. Empeoró. La tarea de definir los límites internacionales del país no se cumplió. El Perú no contaba con fronteras reconocidas mutuamente con sus cinco vecinos a fines de ese siglo. La única excepción fue la frontera fluvial pactada con Brasil en 1851, a lo largo del río Yavarí. Sin embargo, las vastas extensiones amazónicas al norte y al sur de ese río persistieron siendo objeto de complicados litigios entre tres países. Perú, Ecuador y Colombia pugnaban por el amplio territorio entre los ríos Amazonas y Caquetá y, al mismo tiempo, el Perú disputaba la zona circundante al río Acre con Brasil y Bolivia. Las zonas de frontera amazónicas peruanas consistían, en síntesis, en mosaicos de reclamos territoriales superpuestos.

La cambiante organización administrativa colonial legó a los nuevos Estados sudamericanos un conjunto de controversias limítrofes. La separación imprecisa entre las posesiones coloniales españolas y portuguesas aumentó la confusión en la región amazónica compartida por una decena de países. El desconocimiento geográfico solo agravó esa situación. Sin embargo, no obstante la extensión territorial de las zonas amazónicas en litigio, la disputa con Chile por las provincias costeńas de Tacna y Arica opacaría la importancia del resto de las controversias fronterizas. Su sensibilidad derivó de la larga permanencia de población peruana bajo ocupación extranjera, a diferencia del caso de las despobladas zonas amazónicas que no despertaban reacciones de solidaridad similares. Además, su origen como resultado de la derrota militar, y no de la herencia colonial, focalizó el nacionalismo en torno a la disputa con Chile.

La carencia de límites internacionales demandó enfrentar esa situación de extrema vulnerabilidad externa. El riesgo principal consistía en que la acción concertada de los vecinos debilitase de manera significativa la capacidad real del Perú de defender sus reclamos limítrofes. La imagen colectiva y cartográfica del territorio peruano en el año 1900 reflejaba pretensiones nacionales, no realidades políticas y jurídicas. 
Sin acuerdos de límites vigentes, el Perú no contaba en las zonas de frontera con divisiones políticas reconocidas y amparadas jurídicamente, sino tan solo con aspiraciones territoriales, puesto que, en última instancia, la delimitación es la que confiere legitimidad internacional a la soberanía nacional.

A inicios del siglo XX la Cancillería peruana encaró el reto de abordar las controversias fronterizas pendientes con todos los vecinos. La ofensiva diplomática estuvo dirigida a resolver todos los litigios limítrofes subsistentes con Ecuador, Colombia, Brasil y Bolivia, mientras trataba, a la vez, de encontrar una vía para solucionar la disputa con Chile, esfuerzo que enfrentaba la negativa chilena a cesar de ocupar las provincias en pugna. No obstante las expectativas iniciales, las controversias sobre la frontera norte demandarían más esfuerzos y mayor tiempo que lo previsto para ser resueltas y, entre tanto, se lograría alcanzar el acuerdo de límites que solucionaría el litigio con Chile. La ratificación en 1942 del acuerdo limítrofe con Ecuador marcaría la conclusión de la delimitación de la integridad del territorio nacional. En consecuencia, el período entre los años 1902 y 1942 constituyó el primer ciclo durante el cual la diplomacia peruana concentró sus esfuerzos en solucionar las controversias de límites con todos los vecinos del país.

Antes que terminara de demarcarse en el terreno la última frontera terrestre delimitada por el Perú empezaron a surgir nuevas controversias fronterizas. El cumplimiento de la tarea de concluir la ejecución de los tratados de límites con Chile y Ecuador quedaría postergado hasta fines del siglo XX. La inestabilidad generada por la persistencia de controversias sobre límites produciría incidentes militares e incluso conflictos bélicos. De hecho, la disputa entre el Perú y Ecuador en la zona de la cordillera del Cóndor es el único litigio limítrofe que provocó conflictos militares entre Estados americanos durante la segunda mitad del siglo pasado. De manera paralela, a partir de mediados de siglo aparecerían las condiciones que desembocarían, décadas más tarde, en litigios sobre la delimitación marítima. Entre los años 1995 y 2014 se llevaría a cabo el segundo ciclo en el cual la diplomacia peruana enfocaría sus acciones en la solución de las nuevas controversias fronterizas que surgieron a lo largo del siglo XX. Durante esa veintena de años la Cancillería del Perú recurriría a todos los mecanismos de solución pacífica de controversias disponibles para culminar la tarea de definir las fronteras internacionales de la integridad del territorio nacional y sus espacios marítimos.

Esos dos largos ciclos de política exterior concentrados en la problemática fronteriza confirman el papel central que esa temática ha desempeñado en la historia de la diplomacia peruana. Suman sesenta años durante los cuales el interés primordial de la Cancillería giró en torno a la definición de las fronteras internacionales, lo cual constituye el esfuerzo sostenido de la diplomacia peruana más prolongado focalizado 
en un interés nacional. Su predominancia en la gestión externa del Perú resulta más evidente si se toma en consideración que esos ciclos suman la mitad del tiempo que ha transcurrido desde inicios del siglo pasado.

\section{De la ausencia de fronteras a la delimitación fronteriza: 1902-1942}

Wagner de Reyna (1964, p. 120) señala que el año 1900 la Cancillería peruana contaba en total con una veintena de funcionarios. Los miembros de ese equipo enfrentarían con flexibilidad y perseverancia las controversias fronterizas con todos los vecinos del Perú. Llevarían a cabo negociaciones directas simultáneas con interlocutores distintos y al mismo tiempo se encargarían de preparar los legajos y alegatos para diferentes procesos arbitrales. Combinarían acuerdos alcanzados entre las partes con decisiones de terceros y estarían dispuestos a renegociar hasta encontrar fórmulas mutuamente aceptables que fuesen efectivas. En suma, exhibirían su determinación de cumplir la tarea largamente postergada de definir los límites internacionales del país.

La ofensiva diplomática peruana enfocó primero los problemas limítrofes pendientes con Bolivia y Brasil. En 1902 el Perú acordó con Bolivia la delimitación de la zona andina que correspondía en gran medida a las divisiones administrativas usadas a lo largo de la colonia. El sector amazónico al norte era más complicado porque involucraba la disputa entre Perú, Brasil y Bolivia por la zona del Acre. Esa zona venía siendo objeto de mayor atención política de Brasil desde 1898, en la medida que ahí aumentaron los conflictos entre sus colonos y las autoridades bolivianas. El Perú convino con Bolivia en someter la delimitación del sector de frontera amazónico a arbitraje de Argentina. Con Brasil acordó un modus vivendi sobre la base del cual se iniciarían negociaciones para determinar los límites desde la naciente del río Yavarí hasta la frontera con Bolivia.

El reemplazo en Brasil en 1889 de la monarquía parlamentaria por la república modificó la dinámica política regional. Los militares que dirigieron los primeros gobiernos republicanos brasileños enfilaron la política exterior hacia la definición de sus numerosas fronteras internacionales. Primero se concentraron en determinar mediante arbitrajes los límites con Argentina y con las colonias europeas vecinas hacia el norte. En esa coyuntura apareció la figura de José Maria da Silva Paranhos, el barón de Rio Branco, como protagonista clave de la diplomacia brasileña. A partir de 1898 Brasil centraría su atención en la situación crecientemente conflictiva en la zona del Acre que disputaba con Bolivia y Perú.

De hecho, el canciller brasileño Rio Branco conseguiría en 1903 un acuerdo muy favorable con Bolivia para fijar los límites de la región del Acre, reduciendo de manera significativa el área fronteriza que quedó pendiente definir con el Perú. Bolivia, por 
su parte, al año siguiente, en 1904, suscribió y ratificó su acuerdo de límites con Chile, de manera tal que tan solo quedó en discusión en esa zona la situación fronteriza definitiva de Tacna y Arica. Chile para ese entonces ya había establecido en 1902 sus límites con Argentina y tras la celebración del tratado limítrofe con Bolivia solo le restaba resolver la controversia con el Perú.

La intensificación de la dinámica política regional motivó la reacción política peruana. De un lado, el ritmo impuesto desde Brasil por la gestión del canciller Rio Branco reevaluó la prioridad de las negociaciones sobre las divisiones de los espacios amazónicos. De otro lado, Chile, una vez fijadas sus fronteras con Argentina y Bolivia, continuó posponiendo encontrar un mecanismo para resolver la disputa con Perú, con la intención de retener las provincias de Tacna y Arica, tras haberse cumplido desde 1893 el plazo pactado para liquidar la controversia mediante consulta plebiscitaria. El malestar producido por las dilaciones de Chile provocó que en 1901 el Perú rompiese relaciones diplomáticas con ese país.

El año 1904 el Perú reanudó el proceso arbitral para que España resolviera la larga disputa territorial con Ecuador. Ese era el litigio que abarcaba mayor cantidad de territorio en discusión, tomando en consideración las aspiraciones máximas de las partes. Ambos países reclamaban la totalidad de la zona de selva que se extiende desde las laderas orientales de los Andes, entre los ríos Amazonas y Caquetá, hasta la frontera con Brasil establecida en 1851, a lo largo de la línea Apaporis-Tabatinga. En consecuencia, la decisión arbitral española también tendría el efecto colateral de dilucidar los alcances de la controversia limítrofe que restaría con Colombia, dependiendo del resultado del arbitraje. Conforme a las aspiraciones máximas del Ecuador, su frontera con el Perú debía extenderse a lo largo del río Amazonas hasta el límite con Brasil, dejando en ese caso sin colindar al Perú y Colombia. Por el contrario, la máxima aspiración territorial del Perú alcanzaba las laderas andinas, de modo tal que compartiría toda la región amazónica tan solo con Colombia.

La Cancillería brasileña acordó en 1904 con Ecuador que si el arbitraje español favoreciese sus aspiraciones, ambos países respetarían la línea Apaporis-Tabatinga como límite común. El año 1907 alcanzó un acuerdo similar con Colombia. Estipuló que igualmente se reconocería dicha línea geodésica o imaginaria como separación territorial con Brasil, una vez que Colombia esclareciese su disputa amazónica con Perú y Ecuador. Ese acuerdo también estableció los límites entre Brasil y Colombia al norte del río Caquetá. En suma, el canciller Rio Branco exhibió realismo político y aseguró que, cualquiera fuera el resultado del arbitraje ante España, de todas maneras quedaría reconfirmada la línea Apaporis-Tabatinga como límite entre Brasil y la vasta zona amazónica en disputa entre Perú, Ecuador y Colombia. 
Ante ese escenario regional, la Cancillería peruana enfocó su atención en continuar preparando los alegatos para los arbitrajes en curso con Argentina y Espańa y prosiguió efectuando gestiones con Brasil y Colombia para buscar alternativas de solución a las controversias restantes. Su ofensiva diplomática comenzó a fructificar en 1909. En abril de ese año, Perú y Colombia acordaron suspender sus tratativas fronterizas hasta conocer el resultado del entonces inminente arbitraje espańol sobre la disputa peruano-ecuatoriana. En septiembre Perú logró el tratado con Brasil que determinó los límites pendientes desde la naciente del río Yaraví hasta el punto más al norte de la frontera con Bolivia. Ese mismo mes, tras renegociar con Bolivia los términos del laudo arbitral emitido por el gobierno argentino, el Perú suscribió el tratado de límites que definió la totalidad de su frontera común. La demarcación en el terreno de las líneas de frontera convenidas en 1909 con Brasil y Bolivia se llevó a cabo sin mayores tropiezos y por primera vez en la historia quedó fijada en su integridad la frontera oriental del Perú, desde la confluencia de los ríos Amazonas y Yavarí, en el norte, hasta el punto en la sierra sur donde aún hoy coinciden los límites del Perú, Bolivia y Chile.

De manera paralela, persistió siendo un objetivo político prioritario definir la frontera norte del país, de conformidad con la decisión arbitral de la corona española. Ningún tramo de dicha frontera estaba delimitado. Si bien los sectores fronterizos poblados de la costa y sierra contaban con registros de propiedades de los nacionales de cada país, la región amazónica carecía de divisiones de facto claras. Esa región persistía escasamente poblada y sin mayor conocimiento preciso de sus características geográficas, más allá de los principales cursos fluviales. Los títulos coloniales sometidos al parecer del monarca español combinaban argumentos históricos, jurídicos y geográficos de distinta índole y demandaron análisis exhaustivos de la documentación colonial de parte del consejo real que asesoró al rey de España en el estudio del caso.

De acuerdo a las perspectivas del gobierno peruano, la conclusión de la delimitación de la frontera oriental del Perú y la solución de la disputa con Ecuador permitirían concentrar los esfuerzos diplomáticos en la cuestión de Tacna y Arica, la controversia limítrofe más sensible para la población peruana. El empantanamiento continuo de esa disputa reflejaba la intención chilena de impedir que el Perú recuperara ambas provincias. El limbo jurídico en el cual se encontraba el caso favorecía el mantenimiento de statu quo bajo ocupación chilena, con hostigamiento a la población peruana y mayor número de acciones de los gobiernos de Chile dirigidas a fortalecer su presencia. El aumento de las fricciones bilaterales por el litigio provocó en 1909 una segunda ruptura de relaciones diplomáticas entre el Perú y Chile, tras el quiebre previo ocurrido el año 1901. 
Sin embargo, no obstante las expectativas peruanas, el arbitraje español fracasó en 1910. Antes que el rey de España emitiera su fallo, el gobierno ecuatoriano adelantó que no lo aceptaría. Adujo que habiendo tomado conocimiento del criterio del consejo real hispano, no consideraba que la propuesta preliminar satisfacía sus principales aspiraciones territoriales, razón por la cual calificó como inaceptable el laudo que presentaría el árbitro. Ante ese escenario, el rey de España se inhibió de expedir su decisión y se cerró la posibilidad de resolver la controversia mediante procedimiento arbitral.

El fracaso del arbitraje español tuvo consecuencias nefastas para el Perú. En primer lugar, demolió la confianza con Ecuador y eliminó cualquier posibilidad factible de encontrar a mediano plazo algún tipo de arreglo territorial con ese país. En segundo lugar, el alcance de la controversia limítrofe con Colombia quedó completamente indeterminado. De hecho, la incertidumbre provocada por la ausencia de una decisión arbitral generó un incidente militar entre el Perú y Colombia en la localidad de La Pedrera en el río Caquetá. Para resolverlo las cancillerías peruana y colombiana acordaron en 1911 que sus posiciones militares en ese río tuviesen tan solo carácter provisional, sin expresar ningún tipo de reconocimiento oficial en cuanto a sus respectivos reclamos limítrofes. Sin embargo, el efecto más negativo fue que la frustración de la vía arbitral para resolver la disputa amazónica dejó el camino abierto para que los gobiernos de Ecuador y Colombia intentasen alcanzar un arreglo directo entre ellos, en detrimento de los intereses del Perú, el escenario político regional que constituía siempre el riesgo latente para la Cancillería peruana. Además de ello, en Lima permanecía viva la inquietud que los gobiernos de Ecuador y Chile presionaran conjuntamente para definir las disputas que mantenían de manera simultánea con el Perú.

Los logros alcanzados por Torre Tagle en el ámbito fronterizo durante la primera década del siglo XX contrastaron con los retrocesos ocurridos a lo largo de la década siguiente. Las gestiones con Ecuador y Colombia quedaron congeladas y los planes chilenos de retener Tacna y Arica quedaron claros. En 1912, al acercarse el vigésimo aniversario del incumplimiento del plazo convenido para celebrar el plebiscito, la Cancillería de Chile propuso que la consulta pendiente se llevara a cabo en 1933, es decir, cuando se cumpliera medio siglo de ocupación chilena de los territorios en disputa. La intención chilena de preservarlos era innegable. La propuesta obviamente produjo el rechazo previsible en el Perú, así como el malestar nacionalista que contribuyó a la caída del gobierno presidido por Guillermo Billinghurst, quien contempló la posibilidad de admitir la discusión del planteamiento chileno.

Entre tanto, Ecuador y Colombia adoptaron juntos la decisión más negativa para los intereses del Perú. En 1916 firmaron un acuerdo que estableció sus límites desde 
la costa hasta la frontera con Brasil. En la zona oriental, ambos países simplemente dividieron entre ellos toda el área en disputa con el Perú entre los ríos Amazonas y Caquetá. Emplearon el río Putumayo como límite fluvial entre ellos, hasta el río Napo, y acordaron que a partir de ahí el territorio de Colombia alcanzara la ribera norte del río Amazonas hasta Brasil. Como resultado de ello, la frontera del Ecuador con el Perú seguiría por el río Marañón hasta el tramo inicial del Amazonas y el resto del curso de este último limitaría a Colombia y Perú, hasta la frontera con Brasil. En otras palabras, conforme al acuerdo colombo-ecuatoriano, la frontera norte del Perú en la Amazonía quedaba restringida por los cursos de los ríos Marańón y Amazonas.

El desafío para el Perú era evidente. Tenía que evitar que el acuerdo colombo-ecuatoriano se consolidara y que sus efectos políticos y jurídicos adquiriesen carácter definitivo. Para tal efecto tendría que encontrar un curso de acción que le permitiese alcanzar con alguna de las otras dos partes un arreglo que reconociera los reclamos territoriales peruanos al norte del río Amazonas. La opción de lograr un arreglo alternativo con Ecuador enfrentaba el hecho que el tratado con Colombia satisfacía su aspiración histórica de contar con acceso soberano a las riberas norte de los ríos Marañón y Amazonas, aunque ese límite fluvial no alcanzara su pretensión máxima de prolongarse hasta Brasil. En contraposición, el límite convenido en 1916 a favor de Colombia a lo largo del río Amazonas no colindaba con Ecuador sino con el Perú. Este hecho que dejaba abierta la posibilidad que para Colombia fuera más coherente en términos políticos y jurídicos convalidarlo más bien con el Perú, el país vecino con el cual compartiría efectivamente ese tramo de frontera fluvial.

Después de la Primera Guerra Mundial, tras la creación de la Sociedad de las Naciones, el Perú intentó infructuosamente plantear la revisión en esa organización del tratado de Ancón de 1883 con Chile. El objetivo peruano era que las provincias de Tacna y Arica fuesen desocupadas de inmediato por el incumplimiento chileno del acuerdo bilateral. Sin embargo, la elección en 1920 de Arturo Alessandri como presidente de Chile modificó la dinámica de la disputa. Él planteó resolver a la brevedad la controversia celebrando el plebiscito que su país hasta entonces había rehuido llevar a cabo. El Perú rechazó la propuesta de la Cancillería chilena. Sostuvo que solo procedía devolver las provincias que permanecían ocupadas sin ningún amparo legal. Las gestiones entre ambos países prosiguieron a lo largo del año 1921 sin que se acercaran a acuerdo alguno, lo cual creó las condiciones para que el gobierno de Estados Unidos ofreciera arbitrar la discusión sobre la celebración del plebiscito. Las partes aceptaron el ofrecimiento y enviaron delegaciones a Washington para negociar los parámetros del arbitraje.

Ese fue el contexto específico en el cual el canciller peruano Alberto Salomón inició negociaciones limítrofes con Colombia, mientras comenzaba el proceso arbitral para 
resolver la disputa sobre Tacna y Arica. El acuerdo de límites alcanzado en 1922 con Colombia estableció que el río Putumayo constituiría el límite entre ambos países, hasta un punto cercano al Brasil en el cual la línea de frontera descendería al Amazonas y continuaría por ese río hasta el límite con Brasil. En síntesis, Colombia optaba por asegurar con el Perú un tramo limítrofe más corto en el Amazonas que el que había pactado seis años antes con Ecuador. En contrapartida, reconocía como frontera con el Perú más de 90 por ciento del curso del Putumayo al oeste del Brasil. En otras palabras, la controvertida concesión a Colombia de la zona conocida como el «trapecio de Leticia» - por el nombre de la localidad peruana ubicada en la ribera norte del río Amazonas aledańa a Brasil— logró que la soberanía peruana fuera reconocida en la región amazónica hasta el río Putumayo. De esa manera quedó sin amparo jurídico la frontera fluvial a lo largo de los ríos Marañón y Amazonas convenida por Colombia y Ecuador en 1916, razón por la cual Ecuador rompió relaciones diplomáticas con Colombia al conocer el acuerdo de límites que suscribió con el Perú.

Como resultado del arreglo con Colombia de 1922 el territorio que permaneció en controversia entre el Perú y Ecuador quedó reducido a la división del área amazónica al oriente de los Andes al sur del Putumayo y al norte del Marañón. Dos años más tarde, en 1924, las cancillerías peruana y ecuatoriana acordaron un procedimiento mixto para intentar resolver su controversia limítrofe pendiente. El acuerdo consistió en emprender negociaciones directas y convenir que lo que no fuera objeto de arreglo entre las partes fuera sometido a arbitraje de Estados Unidos.

En 1925 el presidente de Estados Unidos expidió su laudo sobre la disputa de Tacna y Arica. Su resultado sorprendió al gobierno peruano. El árbitro decidió que el tratado de 1883 persistía vigente y, por lo tanto, procedía efectuar el plebiscito para decidir la nacionalidad de las dos provincias ocupadas. El único punto a favor del Perú del fallo fue ordenar la devolución inmediata de Tarata puesto que esa provincia no estaba incluida en el tratado de Ancón. No obstante la decisión arbitral, las condiciones reales primaron y tras dos largos ańos de marchas y contramarchas los propios representantes de Estados Unidos concluyeron en 1927 que no era posible llevar a cabo una consulta popular libre y justa.

La imposibilidad de celebrar un plebiscito justo descarriló la posibilidad de resolver la disputa mediante el procedimiento acordado previamente. Ello impulsó la búsqueda de nuevas fórmulas de solución ante un litigio cada vez más entrampado por el fracaso del reciente arbitraje y su prolongación en el tiempo que para entonces ya sumaba casi medio siglo desde la ocupación militar de ambas provincias. Ante ese escenario empezó a cuajar la opción de separar Tacna de Arica y que la división entre ellas constituyera el límite internacional entre el Perú y Chile. Sobre la base de esa alternativa salomónica se inició la negociación directa que culminó con la firma en 
junio de 1929 del tratado de límites entre ambos países. La provincia de Tacna fue restituida al Perú en agosto de ese año y en julio de 1930 terminó la demarcación en el terreno de la línea de frontera peruano-chilena, desde el océano Pacífico hasta la frontera con Bolivia. Coincidentemente, en agosto de 1930 también concluyó la demarcación de la línea de frontera pactada entre Perú y Colombia.

En síntesis, al cabo de tres décadas de múltiples negociaciones y procesos arbitrales el Perú multiplicó por cinco la extensión de sus límites. El único límite internacional que el Perú tenía el año 1900, el curso del río Yavarí, se prolongaba por 1050 kilómetros. Hacia 1930 el Perú ya había agregado 5600 kilómetros adicionales a su perímetro limítrofe y contaba con fronteras íntegramente reconocidas con cuatro de sus cinco vecinos. Solo restaba concluir la delimitación fronteriza con Ecuador.

La disputa limítrofe con Ecuador demostró ser la más prolongada en la historia del Perú. La controversia comenzó en 1830 con la independencia del Ecuador y concluyó recién el año 1942, cuando ambos países por primera vez ratificaron un tratado de límites bilateral, el Protocolo de Río de Janeiro. Previamente, la disputa había sido objeto de negociaciones directas iniciadas en Washington en 1936. Ambos países habían acordado intentar llegar a un arreglo directo y someter los asuntos irresueltos a decisión arbitral de Estados Unidos, pero esas tratativas se prolongaron infructuosamente durante tres años, hasta 1939, sin que las partes lograran acuerdo alguno. El único avance significativo fue la definición en 1936 de las posesiones de hecho en el territorio en disputa, sobre la base de la ubicación de los puestos militares de cada país. La línea del statu quo posesorio dividía la zona en litigio en áreas similares, en donde los puestos ecuatorianos ocupaban los cursos superiores de los afluentes de los ríos Marañón y Amazonas y los puestos peruanos estaban instalados a lo largo de sus cursos inferiores.

La situación en la zona fronteriza entre el Perú y Ecuador permaneció inestable hasta que se agravó a mediados de 1941. El estallido de enfrentamientos armados en dicha zona escaló con rapidez y a fines de julio de ese año las fuerzas armadas peruanas ocuparon la provincia ecuatoriana costeńa de El Oro. La mediación inmediata de Argentina, Brasil y Estados Unidos detuvo las hostilidades y logró un cese de fuego, bajo supervisión de sus observadores militares. Chile se sumó luego al equipo de mediadores que a partir de octubre encaminó sus gestiones hacia la búsqueda de una solución definitiva al litigio entre el Perú y Ecuador. El esfuerzo mediador continuaba en curso en diciembre de 1941 cuando Estados Unidos ingresó a la Segunda Guerra Mundial, a raíz del ataque japonés a la base naval de Pearl Harbor. El cambio de circunstancias motivó que los mediadores invitaran a los dos países a participar en la conferencia panamericana de cancilleres convocada en Río de Janeiro, con miras a aprovechar el encuentro continental para resolver la disputa peruano-ecuatoriana. 
Durante la reunión de Río de Janeiro los representantes de los países mediadores negociaron por separado con las delegaciones del Perú y Ecuador, planteando propuestas y contrapuestas de líneas de frontera para resolver la disputa. En última instancia, los mediadores insistieron en una fórmula de solución basada en la situación posesoria vigente en 1936, la cual finalmente fue aceptada por ambas partes. La madrugada del 29 de enero de 1942 las delegaciones del Perú y Ecuador se encontraron juntas por primera vez en el salón principal de la Cancillería brasileña para proceder a firmar el tratado de límites denominado Protocolo de Río de Janeiro, cuya ejecución quedó bajo la garantía de los cuatro países que habían llevado a cabo la mediación para alcanzar el acuerdo definitivo. El tratado fue aprobado y ratificado por el Perú y Ecuador y en julio de 1942 los representantes de los dos países iniciaron la tarea de demarcar en el terreno la línea de frontera pactada en la capital brasileña.

De esa manera, tras 120 años como Estado independiente, el Perú logró finalmente cumplir la tarea de delimitar la totalidad de las fronteras internacionales con sus cinco vecinos.

\section{De la delimitación del territorio a las nuevas controversias fronterizas}

La ejecución de los tratados de límites con Chile y Ecuador permaneció inconclusa durante toda la segunda mitad del siglo XX. El tema pendiente con Chile era la entrega de las instalaciones del Perú en el puerto chileno de Arica. En cambio, con Ecuador el desacuerdo sobre la demarcación de un sector de la frontera se transformó en una disputa limítrofe explosiva que hipotecó la relación entre ambos países. Así como nadie previó que tardaría setenta años terminar de ejecutar el tratado suscrito en 1929 con Chile, nadie tampoco imaginó que demandaría más de medio siglo finalizar la tarea de demarcar la frontera pactada con Ecuador en 1942.

Adicionalmente, con el paso del tiempo, la delimitación de los espacios marítimos se convertiría, de manera progresiva, en objeto de controversias bilaterales. Las disputas sobre los límites marítimos serían materia de las principales iniciativas emprendidas por la Cancillería peruana a lo largo de los primeros quince años del siglo XXI.

Curiosamente, el origen de ese conjunto de nuevos problemas fronterizos coincidió en un lapso de tiempo corto. Entre los años 1947 y 1954 sucedieron los hechos que dieron pie a las controversias que fueron resueltas desde 1995 hasta 2014. Si bien los nuevos desacuerdos sobre las zonas de frontera no guardaron relación causal entre sí, algunos de sus aspectos técnicos, jurídicos y geográficos sí estaban vinculados. Asimismo, mientras el cumplimiento de las obligaciones pendientes con Chile sí estuvo sujeto a diversas negociaciones, la disputa con Ecuador se caracterizó más bien 
por la ausencia de voluntad de ambas partes de encontrar una solución negociada al desacuerdo. De modo similar, el diferendo sobre la delimitación marítima con Ecuador fue resuelto por negociación directa de un arreglo bilateral, en tanto que la disputa marítima con Chile no pudo ser abordada mediante ningún mecanismo diplomático o político de solución de controversias y el Perú tuvo que recurrir a la Corte Internacional de Justicia (CIJ).

Tras la Segunda Guerra Mundial, a partir de 1945 surgieron nuevas tendencias en el campo del derecho del mar. En ese contexto, Chile y Perú declararon en 1947 su soberanía y jurisdicción sobre zonas marítimas de 200 millas marinas de extensión desde sus costas. La declaración chilena señaló que establecía esa distancia siguiendo una línea perpendicular a su litoral. La peruana puntualizó que lo hacía siguiendo las líneas de los paralelos geográficos. Si bien los dos métodos de medición eran distintos, sus resultados eran similares debido a la orientación meridiana de la costa chilena. Ninguno de los dos países hizo precisión alguna en esa ocasión sobre el límite marítimo bilateral.

Entre tanto, al interior de la Cancillería ecuatoriana comenzaban a cuajar dos posiciones sobre la conclusión de la demarcación de la frontera delimitada con el Perú. Una posición propugnaba culminar la tarea a la brevedad posible, tomando en consideración que solo restaba efectuarla en un tramo de frontera, el sector de la cordillera del Cóndor, que correspondía a cerca de diez por ciento de la extensión total del límite peruano-ecuatoriano. La otra posición planteaba detener el proceso de demarcación fronteriza y evitar así que esa tarea adquiriese carácter definitivo, con miras a dejar abierta la posibilidad de revisar el límite pactado en Río de Janeiro (Academia Diplomática del Perú, 1996, pp. 92-99).

La segunda posición fue adoptada por el gobierno presidido por Galo Plaza, quien asumió funciones en septiembre de 1948. A fines de ese mes el nuevo canciller ecuatoriano ordenó suspender las labores demarcatorias que en esos momentos se estaban llevando a cabo en la cadena principal de la cordillera del Cóndor. Dichos trabajos no volverían a reanudarse en ese lugar sino hasta que transcurrieran cincuenta años.

La suspensión de la demarcación fronteriza coincidió con la crisis política peruana que desembocó en octubre de 1948 en el golpe militar de Manuel Odría. La decisión ecuatoriana no generó inicialmente discusión bilateral alguna. Sin embargo, un año después, en septiembre de 1949, la Cancillería ecuatoriana planteó a su contraparte peruana estudiar con mayor detenimiento la zona de la cordillera del Cóndor. Señaló que era preciso verificar si la geografía de esa área coincidía con la descripción de la línea de frontera en el tratado de límites. La Cancillería peruana retrucó que ambos países contaban con la información necesaria para cumplir la obligación de terminar 
de demarcar la frontera común y propuso recurrir a la asesoría técnica de Brasil para culminar la tarea pendiente. La Cancillería del Ecuador sostuvo en marzo de 1950 que la realidad geográfica de la zona mencionada no correspondía al límite descrito por la letra del tratado. Afirmó que ambos países debían ponerse de acuerdo en cómo resolver esa situación para cumplir la obligación de culminar la ejecución del tratado de límites. El gobierno ecuatoriano procedió luego a suspender totalmente las labores de la comisión demarcadora de límites.

El 10 de agosto de 1952 el presidente Plaza pronunció su discurso de despedida ante el congreso ecuatoriano. En dicha ocasión señaló que el Protocolo de Río de Janeiro no era ejecutable en el sector de la cordillera del Cóndor. Agregó que su país no aceptaría un límite en esa zona que no reconociera los derechos históricos ecuatorianos de contar con acceso soberano al río Amazonas. A consecuencia de ello, diez años después de la ratificación del tratado de límites entre ambos países, surgió una nueva disputa bilateral limítrofe focalizada en el último sector de frontera que restaba demarcar en el terreno.

Mientras tanto, el día siguiente, el 11 de agosto de 1952, representantes de Chile, Ecuador y el Perú inauguraron en Santiago la primera conferencia tripartita para conservar los recursos marinos. Dentro del marco de la conferencia, el 18 de agosto los tres países firmaron la declaración común mediante la cual proclamaron como política internacional conjunta la soberanía y jurisdicción sobre el mar adyacente a sus costas hasta una distancia de 200 millas marinas. Por insistencia del delegado ecuatoriano, la declaración también indicó que las zonas marítimas de las islas ubicadas cerca de las fronteras internacionales no traspasarían los paralelos geográficos del punto de inicio de los límites terrestres entre los países correspondientes. La Declaración de Santiago de 1952 no contuvo ninguna mención adicional relativa a los límites bilaterales.

Dos años después de la suscripción de la Declaración de Santiago, Ecuador, Chile y el Perú celebraron la segunda conferencia para conservar sus recursos marinos. Los tres países suscribieron en esa ocasión el acuerdo para crear la zona especial de tolerancia que evitara sancionar las violaciones accidentales de las fronteras marítimas. El convenio de 1954 señaló expresamente que establecía dicha zona especial a cada lado del paralelo geográfico que constituye el límite marítimo entre los dos países que corresponden.

De manera paralela, el clima de cooperación entre el Perú y Chile se tradujo en la realización en 1953 de las primeras reuniones bilaterales en las cuales ambos países acordaron efectuar los estudios técnicos conjuntos para la construcción del muelle de atraque, la aduana y la estación ferroviaria que se entregarían al Perú en la ciudad de 
Arica, a fin de cumplir con las cláusulas pendientes del tratado de 1929. Previamente, Chile había ofrecido compensaciones financieras a Tacna a cambio de renunciar a la recepción de dichas instalaciones, pero el gobierno peruano descartó esa propuesta. A partir de 1953 los técnicos de ambos países se reunieron con periodicidad hasta que aprobaron conjuntamente el proyecto de construcción pertinente, pero quedó en discusión el régimen jurídico específico que regularía el uso de las instalaciones. Ese sería el núcleo del desacuerdo que persistiría irresuelto hasta fines del siglo XX.

En suma, a mediados de los años cincuenta quedaron definidos los elementos básicos de los problemas relativos a las fronteras que la Cancillería peruana encararía medio siglo más tarde, entre los años 1995 y 2014.

Visto en retrospectiva, la nueva controversia limítrofe con Ecuador quedó petrificada apenas surgió, sin que en ocasión alguna las dos partes hiciesen siquiera el intento de buscar una solución, ya fuese negociada, arbitral o judicial. Recién a inicios del año 1995 ambos países estarían dispuestos a negociar para encontrar la solución del litigio. Por el contrario, concluir la ejecución del tratado de límites con Chile fue objeto de una serie de esfuerzos de cooperación técnica y de negociaciones diplomáticas, en particular en 1985 y 1993, que no alcanzaron acuerdos definitivos por distintos motivos.

Las controversias relativas a los límites marítimos siguieron otro derrotero. Partieron de una situación de concordancia, sobre la base de acuerdos expresos y sobreentendidos o tácitos, que se tradujo en un statu quo estable que no fue objeto de mayor discusión. El interés político fundamental del Perú, Chile y Ecuador fue promover y defender la llamada tesis de las 200 millas para proteger los recursos dentro de las zonas marítimas de esa extensión. El objetivo común imperante hasta la década de los años setenta fue incorporar esa tesis a los esfuerzos multilaterales efectuados para modernizar el derecho del mar, sin que surgieran mayores desacuerdos respecto a los límites marítimos bilaterales ${ }^{1}$. De hecho, el Perú y Chile instalaron en 1972 faros a lo largo del paralelo geográfico del primer hito de la frontera terrestre para materializar la frontera marítima, en ejecución de acuerdos bilaterales de carácter técnico firmados en ese sentido en 1968 y 1969. Los aspectos controvertidos de la delimitación marítima empezaron a aparecer paulatinamente, una vez que el nuevo derecho del mar quedó consagrado en la Convención de las Naciones Unidas sobre

\footnotetext{
1 Recurriendo al principio de contemporaneidad, Enrique García Sayán (14 de mayo de 1973) expuso en detalle en 1973 el origen y el desarrollo de la tesis de las 200 millas, sin aludir en ningún momento a discusión alguna sobre los límites marítimos bilaterales. Del mismo modo, el artículo de Carlos García Bedoya, entonces influyente secretario general de Torre Tagle, publicado en 1974 referido a los temas de la política exterior peruana, incluyendo el tema marítimo, no hizo ninguna mención sobre alguna controversia pendiente respecto a los límites marítimos con Chile o Ecuador.
} 
el Derecho del Mar de 1982. Recién a partir de entonces comenzaron a expresarse las discrepancias bilaterales que se tornaron en disputas hacia fines del siglo $\mathrm{XX}^{2}$.

El tratamiento de la problemática fronteriza en su conjunto tendió a llevarse a cabo en la Cancillería peruana en compartimientos estanco, sin mayor vinculación en cuanto al manejo de cada asunto específico. Los temas en discusión habían surgido cercanamente en términos temporales, pero sin guardar interrelación en términos políticos y de gestión externa. Esa distinción se mantuvo vigente en el accionar de la Cancillería durante décadas. Por ejemplo, la disputa sobre el límite en la zona de la cordillera del Cóndor provocó en 1981 un conflicto militar entre el Perú y Ecuador, mientras que al mismo tiempo ambos países cooperaban estrechamente con Chile en la fase final de la negociación multilateral que se tradujo en la aprobación en 1982 de la Convención del Mar. En otras palabras, la agudización de la desconfianza política y militar en la frontera amazónica peruano-ecuatoriana contrastó con la cooperación de los dos países en el ámbito multilateral en la temática marítima.

De modo similar, mientras aún progresaba la negociación iniciada con Chile en 1985 para crear un sistema integrado de instalaciones peruanas en Arica, en 1986 se llevó a cabo una gestión diplomática en Santiago en la cual un representante especial peruano planteó por primera vez al canciller chileno la necesidad de definir la delimitación marítima bilateral. Si bien la gestión de 1986 no produjo efecto inmediato con relación al tema de la delimitación marítima, en alguna medida contribuyó a descarrilar las negociaciones en curso sobre las instalaciones en Arica que ya enfrentaban creciente resistencia de ciertos sectores del gobierno chileno (Rodríguez, 2009b, p. 3).

Asimismo, una nueva situación de tensión militar en la frontera con Ecuador ocurrida en 1991 impulsó al año siguiente una iniciativa diplomática ambiciosa pero infructuosa con ese país al conmemorarse medio siglo de la firma del tratado de 1942. El Perú inició al mismo tiempo la negociación con Chile que culminó en 1993 con la suscripción de un acuerdo tentativo, las llamadas Convenciones de Lima, para concluir la ejecución del tratado de 1929. Dichas iniciativas, tal como las anteriores, se efectuaron a través de canales inconexos, sin formar parte de una estrategia integral o una visión común sobre cómo encarar de manera simultánea los desacuerdos pendientes sobre temas fronterizos.

\footnotetext{
2 El periodista chileno José Rodríguez Elizondo (2009a) insistió en afirmar que hubo una relación causal entre las negociaciones emprendidas entre Chile y Bolivia a mediados de la década de 1970 para discutir la posibilidad de intercambiar territorios, con miras a que Bolivia volviese a contar con litoral, y la decisión peruana de demandar a Chile para abordar el litigio de la delimitación marítima. No obstante ello, no hay evidencia que antes de 1986 dicha delimitación haya sido objeto de conversación o gestión alguna entre Perú y Chile.
} 
La dispersión diplomática del Perú cambiaría de manera radical en enero de 1995. A partir de entonces la Cancillería peruana focalizaría su atención y concentraría sus esfuerzos en la solución definitiva de las controversias fronterizas restantes. Así también, mantendría vigente esa dinámica de política exterior a lo largo de un período de dos décadas, hasta marzo de 2014, cuando culminó la demarcación del límite marítimo con Chile, en cumplimiento de la sentencia emitida por la CIJ en enero de ese ańo.

\section{La solución de las nuevas controversias fronterizas: 1995-2014}

El conflicto militar de 1995 con Ecuador cambió el escenario político bilateral y regional. Su violencia, duración y el riesgo que se expandiera fuera de la zona de la cordillera del Cóndor demostraron que la disputa constituía una amenaza para la seguridad regional. Eso motivó que los países garantes del tratado de límites, Argentina, Brasil, Chile y Estados Unidos, asumieran plenamente la responsabilidad de contribuir a la solución de la controversia para concluir su ejecución. Asimismo, el resultado ambiguo de los enfrentamientos militares causó que el acuerdo de cese de fuego incluyera la figura de establecer una zona desmilitarizada en el área fronteriza donde ocurrió el conflicto bélico. Dicha zona quedaría bajo supervisión de observadores militares de los garantes. La combinación de ambos factores indujo al Perú y Ecuador a aceptar el reto de negociar para encontrar la solución definitiva de la disputa fronteriza.

El conflicto militar fronterizo previo, ocurrido en 1981, no produjo solución alguna. Las negociaciones concluyeron tras asegurar el cese al fuego que restituyó la situación fronteriza al statu quo preexistente. El gobierno ecuatoriano persistió en negar la validez del tratado de 1942, tal como venía haciéndolo como política oficial desde 1960. El gobierno peruano continuó reiterando su posición tradicional de considerar improcedente discutir con Ecuador sobre desacuerdos limítrofes. Sin embargo, las condiciones producidas a raíz del conflicto militar de 1995 motivaron que el Perú y Ecuador trastocaran las posiciones políticas básicas que habían sostenido durante décadas. El Ecuador, tras un hiato de 35 años, volvió a reconocer la vigencia del tratado de límites, el Protocolo de Río de Janeiro. El Perú aceptó que era necesario negociar para resolver los desacuerdos bilaterales sobre la frontera común. Con el reconocimiento del tratado de 1942 como marco jurídico vinculante, las partes y los garantes estuvieron en capacidad de emprender el complejo proceso de negociaciones iniciado en febrero de 1995.

El proceso de negociación dirigido por la Cancillería durante más de tres años, hasta octubre de 1998, consistió, en síntesis, en una secuencia ininterrumpida de negocia- 
ciones enfocadas en los distintos aspectos en discusión entre las partes ${ }^{3}$. Durante todo el proceso se mantuvo la desconfianza avivada por el estallido del conflicto militar y la ausencia de experiencias negociadoras previas comparables, razón por la cual la mediación de los garantes resultó siendo clave. La dirección del proceso, sus procedimientos y la composición de los equipos de negociadores variaron a través del tiempo, a medida la negociación se adaptaba al cambio de las circunstancias y configuraba su hoja de ruta sobre la base de los acuerdos y avances parciales. La Cancillería peruana recurrió a todas las variedades de medios de solución de controversias de carácter político o diplomático, pero la modalidad mediadora de negociar por separado con los garantes fue fundamental para alcanzar los acuerdos parciales más difíciles.

El proceso de negociación se dividió en cuatro etapas. La primera transcurrió a lo largo de 1995 y giró en torno a la separación, concentración y desmovilización de las fuerzas militares y la definición de la zona desmilitarizada de quinientos kilómetros cuadrados establecida en el área fronteriza disputada. Esa etapa fue supervisada por la misión de observadores militares de los garantes, la Misión de Observadores Militares Ecuador-Perú (Momep), equipo que permaneció operando en el terreno hasta la conclusión de las labores de demarcación de la línea de frontera finalizadas a mediados de 1999. Dos condicionantes de seguridad permanecieron latentes a lo largo de todo el proceso de negociación. En primer lugar, el fracaso de las negociaciones hubiese provocado el retiro de la misión militar de los garantes y, por ende, el reinicio inmediato de las hostilidades para ocupar la zona desmilitarizada. En segundo lugar, los sectores duros en ambos países mantuvieron viva la amenaza de descartar la opción de una solución negociada para reanudar los enfrentamientos bélicos, aunque no existiese la posibilidad de resolver el diferendo mediante el uso de la fuerza.

La segunda etapa del proceso transcurrió a lo largo de 1996. Estuvo focalizada en definir los parámetros jurídicos de la agenda y los procedimientos de la inédita negociación de fondo en ciernes. Fue dirigida personalmente por los cancilleres de las partes, con el respaldo decidido de los representantes de los garantes. Finalmente, tras tres rondas de negociación previas, en octubre se consiguió, gracias a una mediación intensa de los garantes, firmar el acuerdo de Santiago que estableció la meta de alcanzar un acuerdo global que resolviera, de manera definitiva, el conjunto integral de los desacuerdos entre las partes. En Santiago también se aseguró que el proceso quedara sometido al marco jurídico de los mecanismos de solución de controversias contemplados en el Protocolo de Rio, incluyendo la posibilidad de recurrir a decisiones arbitrales de los garantes.

\footnotetext{
3 Los párrafos dedicados a la negociación llevada a cabo con Ecuador resumen la información contenida en: Boza, 2019, pp. 13-34.
} 
La conclusión de esta etapa fue seguida por dos eventos sorpresivos. En diciembre de 1996 el canciller del Perú, Francisco Tudela, y setenta personas más fueron secuestradas por un grupo terrorista en la embajada japonesa en Lima. Luego, en febrero de 1997, el jefe de Estado ecuatoriano fue destituido por el congreso y el dirigente parlamentario Fabián Alarcón asumió la presidencia interina de su país. Eso significó que las dos partes iniciaran la siguiente etapa del proceso - las conversaciones y negociaciones técnicas y jurídicas - sin contar con quienes habían encabezado la etapa anterior. Bajo esas circunstancias se iniciaron las conversaciones substantivas sobre las controversias fronterizas sostenidas en Brasilia desde abril de 1997. El canciller Tudela y el resto de los rehenes fueron liberados por comandos militares en mayo, pero él renunció a su cargo a mediados de año. Tras la renuncia de Tudela, el jurista Fernando de Trazegnies asumió la presidencia de la delegación negociadora peruana y después, en octubre de 2018, la conducción de la Cancillería.

El contrapunto entre las interpretaciones de las partes desembocó, como era previsible, en creciente tensión entre las delegaciones nacionales, a medida que aumentó la sensibilidad de los temas en discusión. El enfrentamiento se agudizó en septiembre de 1997 al abordarse la controversia central y más explosiva relativa a la delimitación de la frontera en la zona de la cordillera del Cóndor. En esa oportunidad la delegación ecuatoriana reclamó contar con acceso soberano al río Marañón o el Amazonas, en atención a sus aspiraciones históricas. El intento ecuatoriano de desconocer el carácter terrestre, no fluvial, del límite pactado en 1942 correspondiente al sector en disputa provocó el rechazo de la delegación peruana y la consiguiente suspensión del proceso de negociación.

Las perspectivas más factibles en esa coyuntura eran la paralización indefinida de las negociaciones o su fracaso. Sin embargo, gracias a una propuesta imaginativa de los garantes, la lógica procesal del proceso se modificó para reorientarlo en función a los intereses en juego en cuatro áreas claves de la relación entre el Perú y Ecuador: la demarcación de la frontera, la libre navegación fluvial, la integración fronteriza y económica y la confianza y cooperación militar. El reajuste de dirección adoptado en noviembre de 1997 fue un cambio substancial que abrió el camino para encontrar la solución global procurada.

A partir de enero de 1998 cuatro comisiones binacionales emprendieron negociaciones simultáneas en las capitales de los países garantes, bajo la conducción y coordinación de las cancillerías del Perú y Ecuador y con la participación de delegados de los países garantes. Las comisiones encargadas de asuntos de integración en Washington y militares en Santiago alcanzaron con rapidez numerosos acuerdos de beneficio mutuo, mientras que los avances de las comisiones responsables de los temas demarcatorios y de navegación fluvial, reunidas en Brasilia y Buenos Aires, 
respectivamente, quedaron entrelazados. En otras palabras, las negociaciones en Washington y Santiago respondieron al modelo win-win, en el cual la suma de acuerdos aumenta los beneficios para ambas partes, en tanto que en Brasilia y Buenos Aires siguieron en modelo suma-cero, en donde las concesiones ofrecidas en una capital dependían de las compensaciones recibidas en la otra capital.

La resolución de las controversias fronterizas discutidas en Brasilia quedó sujeta a la opinión consultiva de expertos de los garantes. Su papel configuró la modalidad negociadora de una conciliación imparcial para acercar a las partes a una solución definitiva. Por eso las labores de las cancillerías del Perú y Ecuador se concentraron en preparar las argumentaciones finales que serían sometidas a la opinión de los expertos de los garantes. La expectativa era que dichas opiniones especializadas permitirían a las partes resolver los desacuerdos de fondo y concluir el acuerdo global antes del inicio del proceso electoral ecuatoriano programado para fines de mayo de 1998.

Las opiniones expedidas por los expertos de los garantes a inicios de mayo convalidaron la interpretación del Perú respecto a la delimitación de la frontera en la zona de la cordillera del Cóndor y en un área pequeña en el extremo oriental de la frontera, cerca del río Putumayo. En cuanto a un área adicional en discusión, cerca de la confluencia de los ríos Yaupi y Santiago, los expertos opinaron que el límite correspondía a una línea de frontera intermedia que recogía argumentos de ambas partes. El Perú aceptó sin condiciones las tres opiniones y el Ecuador solo aceptó la tercera y rechazó las dos primeras. El impase resultante no pudo ser resuelto por la comisión concernida ni mediante las reuniones de vicecancilleres y de cancilleres celebradas en mayo y en julio.

El entrampamiento de la negociación alentó la desestabilización militar que se agudizó a medida que se acercó la transmisión de mando presidencial en Ecuador prevista para el 10 de agosto. La reanudación de las hostilidades fue inminente ante la cercanía física de las tropas movilizadas en la zona de frontera sin demarcar. Solo gestiones de último minuto de la Cancillería peruana con los garantes evitaron que se reiniciaran los enfrentamientos militares y, como medida provisional, la Momep extendió el área bajo su supervisión a toda la zona fronteriza aún pendiente de demarcación.

Fue en ese contexto que los presidentes del Perú y Ecuador empezaron a sostener encuentros directos para tratar de lograr el acuerdo global perseguido e iniciaron la etapa netamente política del proceso. El representante especial de Estados Unidos, Luigi Einaudi, solía repetir que había que aprovechar la ventana de oportunidad aún abierta antes que se cerrara por no ser capaces de alcanzar un acuerdo final. Las reuniones presidenciales aumentaron su frecuencia en septiembre y octubre, con el 
respaldo decidido del mandatario brasileño, pero sin lograr su cometido. Cuando los jefes de Estado llegaron a la conclusión que no les era posible llegar al acuerdo final definitivo mediante negociaciones directas, solicitaron a sus homólogos de los países garantes ofrecer una alternativa de solución.

Los garantes aceptaron la solicitud a condición que la propuesta de sus presidentes contara con la aprobación previa de los congresos y gobiernos del Perú y Ecuador, de manera tal que adquiriera carácter arbitral y, por tanto, fuese de cumplimiento obligatorio. Bajo el amparo de esa figura los mandatarios de los garantes emitieron la propuesta que validó las opiniones de sus expertos de los garantes sobre la línea de frontera y, a la vez, concedió al Ecuador la propiedad de un kilómetro cuadrado ubicado en territorio peruano donde se habían producido los enfrentamientos de 1995. Ello permitió la suscripción el 26 de octubre de 1998 del acuerdo global que resolvió todos los desacuerdos pendientes entre el Perú y Ecuador. En mayo de 1999 se instaló en una de las cimas de la cordillera del Cóndor el último hito de frontera restante para culminar la demarcación en el terreno del límite peruano-ecuatoriano.

La confianza fortalecida entre las autoridades del Perú y Chile durante la prolongada negociación con Ecuador facilitó la decisión de emprender nuevas negociaciones para concluir la ejecución del tratado de 1929, mediante la entrega al Perú de las instalaciones para su servicio ubicadas en Arica. Previamente, la Cancillería peruana había tomado la decisión de retirar del Congreso las Convenciones de Lima suscritas en 1993 con Chile. La polémica interna sobre el régimen privado previsto para la administración de las instalaciones que Chile entregaría hizo inviable insistir en su aprobación parlamentaria. En marzo de 1996 el gobierno chileno también retiró esos acuerdos tentativos del proceso de aprobación legislativa.

El entonces canciller del Perú, Fernando de Trazegnies (2013, pp. 427-431), aprovechó la cumbre APEC celebrada en noviembre de 1998 para reunirse con su homólogo chileno y proponerle reiniciar negociaciones sobre los asuntos pendientes del tratado de 1929. También le planteó trabajar sobre la base del punto de partida que la empresa pública peruana de puertos comerciales se encargara de la administración del muelle al servicio del Perú en Arica. Tras los preparativos llevados a cabo en la cancillería, las delegaciones de ambos países celebraron su primera reunión de trabajo en Lima en marzo de 1999.

En total se llevó a cabo una docena de rondas de reuniones bilaterales durante ese año. Las primeras seis se efectuaron sin mayores contratiempos, enfocadas en los diversos aspectos técnicos referidos a las regulaciones para el muelle, la aduana y la estación ferroviaria. En julio surgió un primer impase cuando la delegación chilena planteó reabrir los acuerdos parciales ya logrados en cuanto a la administración del 
puerto. La situación fue objeto de tratativas directas entre los cancilleres de ambos países, quienes convinieron que en la próxima reunión celebrada en agosto las delegaciones más bien ratificaran los acuerdos técnicos previos para que la negociación continuara en marcha.

En septiembre de 1999 las negociaciones se entramparon nuevamente. El debate en esa ocasión se estancó en torno a la competencia que podía suscitar el muelle del Perú al comercio del resto del puerto. La discusión fue objeto de una serie de sesiones llevadas a cabo en Estados Unidos, aprovechando la presencia temporal en ese país de los cancilleres del Perú y Chile. Las dificultades para lograr un acuerdo sobre el tema en discrepancia amenazaron con descarrilar el esfuerzo negociador iniciado casi un año antes. Ante la perspectiva de producirse otra vez una negociación frustrada, ambos cancilleres se reunieron, primero en Washington y después en Nueva York, para tratar de encontrar una solución que destrabara las negociaciones. Finalmente, acordaron que todos los muelles de Arica tendrían tarifas similares para evitar la competencia por precio entre ellos. Una reunión adicional celebrada en octubre permitió resolver las dudas persistentes sobre el destino de la carga que podía ser desembarcada en el muelle al servicio del Perú. Con ese entendimiento quedó convenido el contenido del acuerdo final.

En noviembre se llevaron a cabo las dos reuniones finales para redactar el acuerdo definitivo y sus anexos técnicos. Seguidamente, el 13 de noviembre de 1999 los cancilleres del Perú y Chile firmaron el Acta de Lima de Ejecución del Tratado de 1929. Luego, el 14 de febrero del año 2000 el gobierno chileno hizo entrega oficial en Arica de las instalaciones al servicio del Perú, más de setenta años después de la suscripción del tratado de límites (Trazegnies, 2013, pp. 435-456).

En síntesis, mediante negociaciones llevadas a cabo, casi de manera ininterrumpida, desde febrero de 1995, cinco años después, en febrero del año 2000, la Cancillería peruana concluyó la ejecución de los tratados de límites con Ecuador y Chile. La tarea había permanecido pendiente de ser finalizada durante siete décadas en el caso de Chile y más de medio siglo con Ecuador. El siglo XX se había iniciado sosteniendo disputas de límites muy sensibles y complicadas con ambos países y recién al finalizar el siglo se logró alcanzar los acuerdos complementarios necesarios para culminar la implementación de esos tratados limítrofes. Sin embargo, no se había terminado de concretar la consecución de esos objetivos claves para la política exterior peruana cuando ya se habían producido los hechos que desembocarían en las controversias sobre la delimitación de los espacios marítimos con esos mismos dos vecinos.

En 1997 Chile se adhirió a la Convención del Mar, instrumento internacional que incluye la obligación de depositar en la Organización de las Naciones Unidas (ONU) 
los mapas oficiales de los límites marítimos y las líneas de base de los Estados parte. Para tal efecto, al año siguiente, en 1998, la armada chilena introdujo en la carta náutica de Arica la impresión de un límite marítimo, a lo largo del paralelo geográfico del primer hito de la frontera entre el Perú y Chile. También suprimió de ese mapa el pequeño tramo de la línea de frontera terrestre demarcada entre el mar y dicho hito. Esa adulteración cartográfica respondió al objetivo de fortalecer el argumento chileno que el límite marítimo bilateral había sido establecido a lo largo del paralelo geográfico mencionado.

En septiembre de 2000, Chile incluyó la nueva edición de su mapa oficial de Arica entre las cartas náuticas que depositó en la ONU. Al tomar conocimiento de dicho hecho la Cancillería peruana presentó a Chile, el 20 octubre de 2000, la nota diplomática de protesta en la cual sostuvo que, ante la inexistencia de un tratado de delimitación marítima entre ambos países, no reconocía la frontera marítima introducida por Chile en su cartografía oficial. Años más tarde, la sentencia de enero de 2014 de la CIJ señalaría que la nota peruana de octubre de 2000 constituyó el punto de partida de la controversia jurídica sobre el límite marítimo con Chile.

En noviembre de 2000 el entonces presidente Alberto Fujimori se fue del Perú y renunció a su cargo mediante el envío de un facsímil, ante lo cual el presidente del congreso, Valentín Paniagua, asumió la presidencia transitoria del país. En esa coyuntura, el gobierno chileno respondió a fines de ese mes que la delimitación marítima había sido establecida mediante los acuerdos tripartitos suscritos por ambos países y Ecuador en 1952 y 1954 y, además, materializada en el terreno a lo largo del paralelo del hito número 1, mediante los acuerdos bilaterales firmados en 1968 y 1969. En diciembre el gobierno peruano reiteró que no había límite marítimo entre ambos países por la ausencia de un tratado bilateral en la materia. Seguidamente, a inicios de 2001, la Cancillería peruana informó a la ONU que los mapas depositados por Chile incluían un límite marítimo con el Perú que no estaba amparado en ningún tratado limítrofe.

En abril de 2001 se hizo de conocimiento público la controversia colateral adicional resultante de la adulteración cartográfica efectuada por Chile en 1998. Al suprimir de sus mapas la línea de frontera entre el mar y el primer hito (el Hito No. 1) Chile pretendía desconocer ese pequeño tramo del límite pactado en 1929 desde el océano Pacífico. La instalación de una caseta de vigilancia chilena al noroeste de dicho tramo limítrofe produjo la polémica pública entre ambos países. El gobierno del Perú exigió el retiro inmediato de su territorio de la caseta chilena. El gobierno de Chile se negó inicialmente a hacerlo. Adujo que el límite terrestre en esa zona había sido modificado en 1968 y 1969 para que siguiera el paralelo del hito hasta el mar. Ante la insis- 
tencia peruana, la Cancillería chilena informó que retiraría la caseta, pero señaló que lo haría para evitar incidentes mayores e indicó que ello no expresaba reconocimiento de la posición sustentada por el Perú.

A partir de entonces ambos países efectuarían diversas acciones para fortalecer sus respectivas posiciones ante la contienda jurídica que empezó a vislumbrarse. El Perú retiraría las reservas que mantenía al Pacto de Bogotá suscrito en 1948 para recurrir a la CIJ, mientras que Chile reafirmaría su posición oficial que no tenía asuntos limítrofes pendientes con el Perú. En julio del año 2004 el Perú propondría oficialmente a Chile iniciar negociaciones para delimitar sus espacios marítimos. Chile respondería reiterando que no había ningún asunto pendiente que discutir respecto al límite marítimo bilateral. De esa manera se agotó la posibilidad de encontrar una solución negociada a la controversia, lo cual constituía un requisito para presentar una demanda ante la CIJ.

$\mathrm{Al}$ año siguiente, en 2005, el congreso peruano aprobaría la ley de líneas de base del litoral hasta su extremo sur en el punto inicial de la frontera entre el Perú y Chile. El gobierno chileno reaccionó protestando por la inclusión de ese punto inicial, ubicado ligeramente al sur del paralelo donde está instalado el primer hito de la frontera. Esa discusión respondía a la intención chilena de desconocer la línea de frontera entre ese hito y el mar, tal como hizo al suprimirla de sus mapas en 1998, con miras a fortalecer su argumento que el límite marítimo bilateral seguía el paralelo geográfico del hito, según los acuerdos técnicos suscritos en 1968 y 1969.

Irónicamente, la insistencia chilena de poner en discusión el tramo inicial de frontera terrestre provocaría como resultado no buscado la activación del proceso para demandar a Chile ante la CIJ. En efecto, en enero de 2007 la Cancillería peruana tomó conocimiento que el congreso chileno acababa de introducir una modificación al proyecto de ley para crear una región adicional colindante con el Perú, la región Arica-Parinacota por el nombre de las dos provincias que se desprenderían de Tarapacá para formar la nueva circunscripción administrativa. La modificación introducida a último minuto alteraba el límite establecido en 1929 y planteaba que la línea de frontera terrestre seguía desde el primer hito de frontera hacia el oeste por el paralelo geográfico hasta el mar. La Cancillería peruana protestó de inmediato y exigió que no se aprobase la modificación que contravenía la delimitación pactada en 1929, pero el Congreso chileno igualmente la aprobó. La Cancillería peruana insistió en reclamar la desautorización de dicha alteración del límite común, pero el gobierno chileno promulgó la ley sin retirar la controvertida modificación. La polémica bilateral se apaciguó solo cuando el tribunal constitucional chileno dictaminó que la modificación en cuestión era improcedente y que la ley debía restringirse a señalar que la nueva región limitaba al norte con el Perú, sin hacer mayores precisiones. 
La polémica, sin embargo, convenció al gobierno peruano de la necesidad de recurrir, a la brevedad posible, a la CIJ para resolver la controversia con Chile. En consecuencia, la Cancillería peruana efectuó durante el año 2007 todos los preparativos necesarios para presentar la demanda correspondiente. La preparación incluyó, aparte de llevar a cabo las gestiones para consolidar el frente interno, seleccionar los equipos jurídicos y técnicos, elegir el juez ad hoc, realizar los trámites previos pertinentes en la ONU, elaborar y publicar los mapas oficiales del área en controversia y nombrar al agente que representaría al Perú ante la corte, responsabilidad que recayó en el ex canciller Allan Wagner. Además la Cancillería peruana esperó hasta conocer dos casos marítimos relevantes cuyas sentencias fueron emitidas ese año, los litigios entre Nicaragua y Honduras y entre Guyana y Surinam. Una vez concluido ese conjunto de labores, el equipo de juristas y técnicos peruanos y extranjeros se reunió en Lima para preparar el texto final de la demanda que fue presentada ante la CIJ en enero de 2008.

La preparación y la presentación de los alegatos y las réplicas de la etapa escrita del proceso quedaron bajo reserva en manos del equipo encabezado por Wagner, conforme a los procedimientos y los plazos de la corte de La Haya, en donde la contienda jurídica constituye, por definición, la negación de la negociación. Entre tanto, el Perú y Chile orientaron gestiones diplomáticas hacia Ecuador, con miras a tratar de lograr que su posición resultara más favorable a los intereses correspondientes en litigio en La Haya. El papel clave de Ecuador respondía a su calidad de cosignatario de los acuerdos tripartitos firmados en 1952 y 1954.

Ecuador publicó en 2010 los mapas oficiales de sus límites marítimos con el Perú siguiendo el paralelo geográfico del punto de inicio de la frontera terrestre delimitada en 1942, así como haciendo referencia expresa a los acuerdos tripartitos de 1952 y 1954. Dicha publicación satisfizo las expectativas del gobierno chileno, bajo la lógica que respaldaba su interpretación de dichos acuerdos, tal como la defendía ante la CIJ. El Perú en principio estaba de acuerdo con la frontera graficada en ese mapa ecuatoriano, en tanto consideraba que el criterio de emplear paralelos como límite marítimo respondía a la situación particular de la presencia de islas cerca de la frontera con Ecuador, condición que no se cumplía cerca de la frontera con Chile. No obstante ello, las dudas planteadas por las referencias en el mapa a los acuerdos de los ańos cincuenta motivaron que el gobierno peruano reforzara sus gestiones con el Ecuador (García Belaunde, 29 de enero de 2014, pp. 9-11).

Las tratativas diplomáticas iniciadas con Ecuador dieron fruto en 2011, tras casi doce meses de negociaciones mantenidas en secreto. En mayo de ese año, el Perú y Ecuador establecieron de común acuerdo, mediante intercambio de notas, la delimitación marítima entre ambos países. El acuerdo incluyó las cartas oficiales elaboradas 
conjuntamente que grafican de manera oficial la línea del límite marítimo común en su integridad.

El valor fundamental del acuerdo logrado con Ecuador para efectos del juicio en curso entonces en La Haya radicó en que dejó en evidencia la inexistencia de un tratado de límites marítimos previo con el Perú, no obstante el hecho que ambos países suscribieron con Chile los acuerdos tripartitos de 1952 y 1954. La conclusión era obvia. Si ninguno de los dos países consideraba que había establecido su frontera marítima común mediante los acuerdos suscritos en los años cincuenta, mal podrían calificarse ellos como tratados de delimitación marítima, tal como aducía Chile ante la CIJ. Si bien el acuerdo de límites marítimos entre el Perú y Ecuador fue alcanzado después de la finalización de la fase escrita del juicio en curso en La Haya, el significado jurídico e histórico de su firma fue un elemento central de los argumentos sustentados por el Perú en la fase oral del litigio con Chile que se llevó a cabo en La Haya a fines de 2012.

Tras la celebración de la fase oral del litigio con Chile estaba previsto que la corte elaboraría su sentencia durante el siguiente semestre, pero esa etapa se prolongó hasta fines de enero de 2014, cuando la corte expidió finalmente su sentencia. Como es ampliamente conocido, la corte estableció que el límite marítimo entre el Perú y Chile parte de la intersección de la línea de baja mar y el paralelo geográfico del primer hito de la frontera y sigue por ese paralelo a lo largo de una distancia de 80 millas marinas, punto a partir del cual el límite sigue por una línea equidistante hasta una distancia de 200 millas marinas de las costas de ambos países. La corte también precisó que no le correspondía pronunciarse sobre la ubicación geográfica del punto de inicio de la frontera terrestre, pero señaló que en vista de los tratados suscritos entre las partes su ubicación no coincidía con la del punto de inicio de la frontera marítima.

Ambos países demarcaron el punto de inicio de la frontera marítima y efectuaron juntos los trabajos para graficar en mapas comunes la integridad del límite marítimo establecido por la CIJ. En marzo de 2014 concluyeron esas labores y suscribieron las actas que culminaron la tarea de demarcar la frontera marítima común. En julio de ese año el Perú publicó las cartas del sector sur del dominio marítimo nacional conforme a la delimitación establecida por la corte y demarcada por ambas partes, incluyendo el gráfico que muestra los puntos de inicio del límite terrestre y el marítimo, ubicados ambos a escasa distancia entre sí en la intersección de las dos líneas de frontera correspondientes con el mar.

De esa manera la Cancillería peruana culminó un ciclo de veinte años, iniciado en 1995, durante el cual concentró su acción en la resolución definitiva de las últimas 
controversias respecto a las fronteras internacionales del país que aún quedaban pendientes. Para tal efecto, el conjunto de iniciativas que emprendió a lo largo de ese período implicó recurrir a todos los medios de solución pacífica de controversias internacionales, desde las negociaciones directas y el resto de modalidades de negociación que constituyen los medios políticos o diplomáticos de resolución de controversias, incluyendo la mediación y la conciliación, hasta los medios jurídicos o judiciales que configuran los arbitrajes y juicios ante cortes internacionales. En otras palabras, la Cancillería peruana desplegó entre los años 1995 y 2014 todo el espectro de la acción diplomática, desde la negociación hasta la contienda jurídica, para cumplir con su responsabilidad institucional de concluir la definición de la integridad del perímetro limítrofe nacional, incluyendo la totalidad de su territorio y dominio marítimo.

\section{Conclusión}

La preocupación en torno a la problemática fronteriza del país ha sido una constante en la historia de la Cancillería peruana, pero hubo dos períodos, dos ciclos en los cuales ese interés se expresó en esfuerzos concretos para lograr solucionar las controversias fronterizas. El primer ciclo, desde 1902 hasta 1942, estuvo focalizado en resolver los litigios limítrofes heredados de la colonia y de la guerra con Chile. El segundo ciclo, de menor duración temporal pero por lo mismo más intenso, transcurrió entre los años 1995 y 2014 y estuvo enfocado en solucionar las controversias relativas a las fronteras que surgieron a lo largo del siglo XX.

El primer ciclo derivó, en última instancia, en un conjunto de negociaciones directas, con la excepción del caso con Ecuador que requirió una negociación con la participación protagónica de mediadores. Durante el segundo ciclo la Cancillería peruana empleó más bien todos los medios de solución pacífica de controversias disponibles, desde la negociación directa hasta el litigio judicial ante tribunales internacionales.

La evidencia confirma que el contexto político condicionó los medios empleados y los objetivos concretos perseguidos para cumplir con la obligación de delimitar el territorio nacional y sus espacios marítimos. La solución de las disputas fronterizas depende directamente de sus características y componentes específicos. Los mecanismos de solución pacífica de controversias internacionales tienen que adecuarse a cada caso en particular y su resolución está definida por la satisfacción de los intereses concretos en discusión en cada litigio. Sin embargo, las oportunidades para resolver las disputas y las posibilidades reales de alcanzar esa meta dependen de un conjunto de variables de internas y externas. 
La presencia de la combinación de factores necesarios para encontrar soluciones duraderas no es frecuente, ni depende exclusivamente de la voluntad de las partes. Es preciso aprovechar las oportunidades propicias cuando aparecen y encarar el desafío con la información disponible en ese momento y bajo las condiciones concretas que impone la realidad coyuntural. Los dos ciclos de política exterior focalizados en la solución de las controversias fronterizas reflejan justamente cómo la diplomacia peruana actuó, dentro del marco específico de las condiciones efectivamente presentes, para cumplir la tarea de establecer el conjunto de los límites internacionales del Perú.

\section{Referencias bibliográficas}

Academia Diplomática del Perú - ADP (1996). Selección de Memoranda e Informe Final de George McBride. Repertorio documental. Lima: Ministerio de Relaciones Exteriores del Perú.

Boza, J. (2019). Una mirada retrospectiva al proceso de negociación entre Perú y Ecuador. En F. Novak, S. Namihas y J. Boza (coords.), El proceso de negociaciones entre el Perú y el Ecuador (1995-1998) y los 20 años de los Acuerdos de Paz de Brasilia (pp. 13-35). Lima: Instituto de Estudios Internacionales (IDEI) de la Pontificia Universidad Católica del Perú, Ministerio de Relaciones Exteriores del Perú y Fundación Konrad Adenauer.

García Bedoya, C. (1981). Política exterior peruana: teoría y práctica. Lima: Mosca Azul Editores.

García Belaunde, J.A. (29 de enero de 2014). De límites y presiones. El largo camino a La Haya. El Comercio, Edición Especial. Recuperado de http://3.elcomercio.e3.pe/ doc/0/0/8/1/7/817213.pdf

García Sayán, E. (14 de mayo de 1973). La doctrina de las 200 millas y el derecho del mar. Conferencia en la Universidad de Oxford. Recuperado de: https://dialnet.unirioja.es/ descarga/articulo/5084888.pdf

Rodríguez Elizondo, J. (2009a). De Charaña a La Haya: Chile, entre la aspiración marítima de Bolivia y la demanda maritima de Perú. Santiago de Chile: La Tercera Ediciones.

Rodríguez Elizondo, J. (2009b). Conflicto Chile-Perú: Los hechos que ocultó el derecho. Análisis y propuestas - Politica internacional. Santiago de Chile: Fundación Friedrich Ebert. Recuperado de http://library.fes.de/pdf-files/bueros/chile/06784.pdf

Trazegnies, F. de (2013). Testigo presencial. Lima: Fundación Bustamante de la Fuente.

Wagner de Reyna, A. (1964). Historia fiplomática del Perú, 1900-1945. Lima: Academia Diplomática del Perú. 